\title{
Cine Displacement ENcoding imaging with Stimulated Echoes (cine-DENSE) confirms systolic myocardial dysfunction in asymptomatic patients with type 2 diabetes mellitus: comparison with MR-tagging
}

\author{
Laura Ernande ${ }^{1 *}$, Han Wen ${ }^{2}$, Cyrille Bergerot ${ }^{1}$, Hélène Thibault ${ }^{1}$, Michel Ovize${ }^{1}$, Geneviève Derumeaux', \\ Pierre Croisille
}

From 2011 SCMR/Euro CMR Joint Scientific Sessions

Nice, France. 3-6 February 2011

\section{Introduction}

Diabetic cardiomyopathy contributes to increased cardiovascular mortality in diabetes mellitus (DM) patients and is characterized by a progressive alteration of left ventricular (LV) function. At a preclinical stage, a decrease in systolic myocardial strain has been suggested in echocardiographic studies.

MRI techniques remain the gold standard for quantification of myocardial deformation but only a single study suggested systolic abnormalities in type 2 DM patients with evidence of diastolic dysfunction.

MR-tagging is the most common technique for strain calculation using CMR but is intrinsically limited in measuring transmural variations. Cine-Displacement ENcoding Imaging with Stimulated Echoes(DENSE) has been recently proposed as an alternative that benefits from an increased spatial resolution.

\section{Purpose}

To evaluate whether cine-DENSE and MR-tagging confirm the existence of a sub-clinical myocardial dysfunction in a population of type $2 \mathrm{DM}$ patients with no sign or history of heart disease and normal conventional echo and MRI parameters.

\section{Methods}

37 patients with type $2 \mathrm{DM}(50.6 \pm 5.6$ years, 8 females, HbA1c $7.6 \pm 1.2 \%)$ and 21 age-matched controls (49.7 \pm 8.0 years, 11 females) underwent a CMR study on a $1.5 \mathrm{~T}$ scanner. Subjects were excluded if standard echocardiography showed significant abnormality. After a standard CMR study for conventional LV function assessment, two-dimensional cine-DENSE pulse sequence with short-echo train echo-planar imaging readout and cine-tagging with complementary spatial modulation of magnetization(CSPAMM) were acquired in short axis views at the same basal, mid and apical levels. LV volumes and ejection fraction were measured on cine-MRI images. Regional circumferential maximal systolic $\operatorname{strain}\left(\varepsilon_{c}\right)$ was calculated from cine-DENSE and MR-tagging acquisitions on $16 \mathrm{LV}$ segments. Average maximal systolic strain in each slice and a whole heart mean value $\left(\varepsilon_{\mathrm{c}}\right.$ mean) for each patient were calculated. Post-processing of cine-DENSE acquisitions included adaptive phase-unwrapping and spatial filtering. CSPAMM images were processed using InTag post-processing toolbox (Creatis, Lyon, France) implemented in OsiriX software (Geneva, Switzerland) with motion estimation based on the Sine Wave Modeling approach.

\section{Results}

Standard cine-MRI LV function parameters were normal and comparable between groups (table 1). Whereas LV ejection fraction was similar in the 2 groups, cine-DENSE 
Table 1 Left ventricular function in type 2 diabetes mellitus patients and controls

\begin{tabular}{llll}
\hline & DM patients & Controls & P \\
\hline LVEDV $(\mathrm{mL})$ & $120 \pm 26$ & $129 \pm 28$ & 0.26 \\
LVESV $(\mathrm{mL})$ & $41 \pm 12$ & $41 \pm 12$ & 0.90 \\
LVEF $(\%)$ & $66 \pm 6$ & $68 \pm 6$ & 0.30 \\
\hline $\boldsymbol{\varepsilon}_{\mathrm{c}}$ base MR-tagging & $-0.173 \pm 0.040$ & $-0.200 \pm 0.028$ & 0.004 \\
$\boldsymbol{\varepsilon}_{\mathrm{c}}$ mid MR-tagging & $-0.177 \pm 0.045$ & $-0.220 \pm 0.035$ & $<0.001$ \\
$\boldsymbol{\varepsilon}_{\mathrm{c}}$ apex MR-tagging & $-0.189 \pm 0.056$ & $-0.232 \pm 0.025$ & $<0.001$ \\
$\boldsymbol{\varepsilon}_{\mathrm{c}}$ mean MR-tagging & $-0.179 \pm 0.045$ & $-0.216 \pm 0.025$ & $<0.001$ \\
\hline $\boldsymbol{\varepsilon}_{\mathrm{c}}$ base cine-DENSE & $-0.134 \pm 0.019$ & $-0.155 \pm 0.019$ & $<0.001$ \\
$\boldsymbol{\varepsilon}_{\mathrm{c}}$ mid cine-DENSE & $-0.150 \pm 0.021$ & $-0.174 \pm 0.020$ & $<0.001$ \\
$\boldsymbol{\varepsilon}_{\mathrm{c}}$ apex cine- DENSE & $-0.153 \pm 0.022$ & $-0.193 \pm 0.018$ & $<0.001$ \\
$\boldsymbol{\varepsilon}_{\mathrm{c}}$ mean cine-DENSE & $-0.144 \pm 0.016$ & $-0.171 \pm 0.016$ & $<0.001$ \\
\hline
\end{tabular}

LVEDV= left ventricular end-diastolic volume; LVESV= left ventricular end-systolic volume; $L V E F=$ left ventricular ejection fraction; $\varepsilon_{c}=$ Régional circumferential maximal systolic strain.

showed a significant decrease in $\varepsilon_{\mathrm{c}}$ at basal, mid and apical LV level and in $\varepsilon_{\mathrm{c}}$ mean in the DM group as compared to controls. MR-tagging confirmed a decrease in $\varepsilon_{\mathrm{c}}$ at the $3 \mathrm{LV}$ levels and in $\varepsilon_{\mathrm{c}}$ mean in DM patients as compared with controls.

\section{Conclusions}

Cine-DENSE and MR-tagging confirm subclinical myocardial dysfunction in asymptomatic patients with Type II DM.

\section{Author details}

${ }^{1}$ Louis Pradel Hospital, Lyon, France. ${ }^{2}$ National Heart, Lung, and Blood

Institute, National Institutes of Health", Bethesda, MD, USA.

Published: 2 February 2011

doi:10.1186/1532-429X-13-S1-P280

Cite this article as: Ernande et al:: Cine Displacement ENcoding imaging with Stimulated Echoes (cine-DENSE) confirms systolic myocardial dysfunction in asymptomatic patients with type 2 diabetes mellitus: comparison with MR-tagging. Journal of Cardiovascular Magnetic Resonance 2011 13(Suppl 1):P280.

Submit your next manuscript to BioMed Central and take full advantage of:

- Convenient online submission

- Thorough peer review

- No space constraints or color figure charges

- Immediate publication on acceptance

- Inclusion in PubMed, CAS, Scopus and Google Scholar

- Research which is freely available for redistribution

Submit your manuscript at www.biomedcentral.com/submit 